\title{
A modified prognostic model in patients with diffuse large B-cell lymphoma treated with immunochemotherapy
}

\author{
PEIQI ZHAO ${ }^{1}$, LEI ZHU ${ }^{2}$, LANFANG LI ${ }^{1}$, SHIYONG ZHOU ${ }^{1}$, LIHUA QIU ${ }^{1}$, \\ ZHENGZI QIAN $^{1}$, WENGUI XU ${ }^{2}$ and HUILAI ZHANG ${ }^{1}$ \\ ${ }^{1}$ Department of Lymphoma, Tianjin's Clinical Research Center for Cancer, Key Laboratory of Cancer Prevention and Therapy; \\ ${ }^{2}$ Department of Molecular Imaging and Nuclear Medicine, National Clinical Research Center for Cancer, \\ Tianjin Medical University Cancer Institute and Hospital, Tianjin Medical University, Tianjin 300060, P.R. China
}

Received March 21, 2020; Accepted November 26, 2020

DOI: $10.3892 / \mathrm{ol} .2021 .12479$

\begin{abstract}
In the era of immunochemotherapy, the traditional international prognostic index (IPI) has partially lost its predictive value in diffuse large B-cell lymphoma (DLBCL) and the National Comprehensive Cancer Network-IPI (NCCN-IPI) is unable to effectively identify high-risk patients. Thus, the present study aimed to develop a modified prognostic model (M-PM) to identify high-risk patients that require aggressive treatment. The present study included 169 patients with newly diagnosed DLBCL treated with rituximab, cyclophosphamide, doxorubicin, vincristine and prednisone (RCHOP) or RCHOP-like regimens, between 2011-2017. The results demonstrated that the risk discrimination was improved in the NCCN-IPI compared with the IPI, and patients were divided into four risk groups with a 5-year overall survival rate of 93.8, 76.5, 54.3 and $39.4 \%$, respectively. However, the NCCN-IPI failed to identify the high-risk DLBCL population. The newly developed M-PM presented here included four parameters: Age ( $\geq 65$ years), an elevated lactate dehydrogenase level, Eastern Cooperative Oncology Group score $\geq 2$ and total metabolic tumor volume $\geq 300 \mathrm{~cm}^{3}$. The M-PM also divided patients into four risk groups that comprised 40.8, 23.1, 26.0 and $10.1 \%$ of the patients, and the 5-year survival rates of these groups were $92.4,70.6,52.3$ and $24.5 \%$, respectively. Taken
\end{abstract}

Correspondence to: Dr Huilai Zhang, Department of Lymphoma, Tianjin's Clinical Research Center for Cancer, Key Laboratory of Cancer Prevention and Therapy, Tianjin Medical University Cancer Institute and Hospital, Tianjin Medical University, 24 Huanhu West Road, Tianjin 300060, P.R. China

E-mail: zhanghltch@163.com

Dr Wengui Xu, Department of Molecular Imaging and Nuclear Medicine, National Clinical Research Center for Cancer, Tianjin Medical University Cancer Institute and Hospital, Tianjin Medical University, 24 Huanhu West Road, Tianjin 300060, P.R. China

E-mail: wenguix2010@163.com

Key words: diffuse large B-cell lymphoma, international prognostic index, prognostic model, total metabolic tumor volume together, the results of the present study demonstrated that the M-PM was more accurate compared with the IPI and the NCCN-IPI, which served as an effective tool for identifying patients with DLBCL at high risk of an adverse prognosis.

\section{Introduction}

Diffuse large B-cell lymphoma (DLBCL) is one of the most common subtypes of Non-Hodgkin's lymphoma (NHL) in adults, accounting for $30 \%$ of NHLs (1). DLBCL has significant heterogeneity in clinical manifestations, biological characteristics, and prognosis (2-4). Although $>50 \%$ of patients with DLBCL may be cured by upfront chemoimmunotherapy (2), $40-50 \%$ of patients relapse and/or the disease becomes refractory, and it is estimated that one third of patients will eventually die of the disease (5).

Given the notable heterogeneity within DLBCL, an accurate and reliable prediction tool is essential to optimize the treatment of patients. Since 1993, the international prognostic index (IPI) has become a major clinical predictive tool for the prognosis of patients with DLBCL (6). Based on the number of adverse prognostic factors, four independent risk groups were identified, and the 5-year overall survival (OS) rate was between $26-73 \%$ (6). However, as rituximab significantly improves the prognosis of patients with DLBCL, use of the IPI in identifying high-risk groups is questionable $(7,8)$.

In 2014,Zhou et al (9) proposed the National Comprehensive Cancer Network (NCCN)-IPI based on IPI, which highlights the prognostic effects of age, lactate dehydrogenase (LDH) level and extranodal involvement site. Although previous studies have reported that the NCCN-IPI has better risk stratification than the IPI between low-risk and high-risk DLBCL (5-year OS, $96 \%$ vs. 33\% for NCCN-IPI; 5-year OS 90\% vs. $54 \%$ for IPI), NCCN-IPI fails to identify extremely high-risk populations (10-13). As was the case with its predecessor, the prognostic factors of NCCN-IPI mainly come from the clinical indicators of DLBCL (14). However, the model does not contain information obtained from standardized imaging techniques.

Positron Emission Tomography-Computed Tomography (PET/CT) has great value in the accurate staging, evaluation of efficacy, determination of prognosis and guidance for 
the subsequent treatment of malignant lymphoma (15-17). High fluorodeoxyglucose (FDG) uptake is a surrogate indicator of aggressive biological characteristics of malignant lymphoma (18). The total metabolic tumor volume (TMTV) assessed by PET/CT can be used as an index to measure tumor volume and invasiveness (18). Previous studies have demonstrated that TMTV has a greater prognostic value than Ann Arbor stage and can be used as a prognostic factor independent of IPI $(19,20)$. High TMTV is associated with poor progression-free survival (PFS) (21). Analyses from the GOYA study revealed that higher TMTV is significantly associated with poor prognosis in patients independent of IPI (22). Notably, quantitative tumor imaging indicators, such as TMTV have the potential to replace traditional IPI factors that reflect tumor burden, such as extranodal diseases and Ann Arbor stage (19,20).

Thus, in the era of immunochemotherapy, the present study aimed to design a novel prognostic model of DLBCL composed of standardized imaging techniques and clinical parameters, and to assess its prognostic value in patients with DLBCL.

\section{Patients and methods}

Patients and data collection. This retrospective study included 169 patients treated at Tianjin Medical University Cancer Institute and Hospital between January 2011 and December 2017. The present study was approved by the Institutional Review Board of the Tianjin Medical University Cancer Institute and Hospital (Tianjin, China) and written informed consent was obtained from all the patients. The inclusion criteria were as follows: i) Age (>18 years), regardless of sex; ii) CD20 positive patients with DLBCL who had not received treatment in the past and iii) first-line treatment options were rituximab, cyclophosphamide, doxorubicin, vincristine and prednisone (RCHOP) or RCHOP-like regimens. Diagnosis of DLBCL was confirmed by Dr. Meng and Dr. Zhai from the Department of Pathology at The Tianjin Medical University Cancer Hospital (Tianjin, China). The immunohistochemical markers CD10, BCL-6 and multiple myeloma oncogene 1 were detected and patients were subsequently divided into germinal-center B-cell-like (GCB) or non-GCB subtypes, using Hans' algorithm (23). All patients were restaged according to the Lugano classification system (24). Bulky disease was defined as a measurable tumor mass $\geq 7.5 \mathrm{~cm}$ in diameter.

The IPI includes five risk factors: Age ( $>60$ years), LDH above upper normal value, the involvement of extra-lymph node tissues or organs $>1$, Eastern Cooperative Oncology Group (ECOG) score $\geq 2$ and disease stage III/IV (6). According to the number of poor prognostic factors, IPI divided patients into four groups: Low-risk group, low-intermediate risk group, intermediate-high risk group and high-risk group. The NCCN-IPI relies on the same five poor prognostic indicators as the IPI, but the patient's age, elevated LDH levels and specific extranodal involvement are more heavily weighted (9). Patients were also divided into four groups by the NCCN-IPI (Table I).

PET imaging. All patients underwent FDG PET/CT scanning prior to chemotherapy. PET/CT studies were performed according to protocols and manufacturer guidelines (25). A total of two experienced nuclear medicine experts calculated the quantitative parameters. The TMTV was obtained by summarizing the metabolic volume of all lymph nodes and extra-lymph node lesions. Bone marrow involvement was included in the volume measurement only in the presence of focal uptake. The spleen was involved if the focal or disseminated uptake was $>150 \%$ of the liver background.

Statistical analysis. Statistical analysis was performed using SPSS 22 software (IBM Corp.). OS time refers to the time from random assignment to mortality for any reason (lost follow-up is the last follow-up time; patients who are still alive at the end of the study are the end date of follow-up) (26). PFS refers to the time from the start of randomization to the first tumor progression, relapse, mortality or last contact (26). The Kaplan-Meier method was used to calculate OS and PFS time, and the log-rank test was used to determine statistically significant differences between the two groups. Univariate and multivariate analyses were performed according to the Cox regression model to assess prognostic value. $\mathrm{P} \leq 0.05$ was considered to indicate a statistically significant difference.

\section{Results}

Clinical characteristics of patients. The clinical characteristics of the 169 patients are presented in Table II. The patients' median follow-up time was 60 months. All patients received induction chemotherapy containing $\mathrm{R}-\mathrm{CHOP}$ or RCHOP-like regimens, and 88.8 and $11.2 \%$ received RCHOP and R-mini-CHOP, respectively. A total of 49 patients (29.0\%) were $>65$ years old and men have slightly more cases than women $(53.3 \%)$. There were 25 patients (14.8\%) with bulky disease (mass $>7.5 \mathrm{~cm}$ ). The involvement of bone marrow occurred in 23 cases $(13.6 \%)$. A total of 52 patients $(30.8 \%)$ were diagnosed at stage I-II, while the remaining 117 patients $(69.2 \%)$ were diagnosed at stage III-IV. A total of 99 patients $(58.6 \%)$ had elevated LDH levels, and 28 patients (16.6\%) had an ECOG performance status $\geq 2$. Extranodal involvement was present in 43 patients (25.4\%). According to the IPI, 56 patients (33.1\%) and 35 patients $(20.7 \%)$ had low or low-intermediate IPI scores, respectively, whereas 44 patients $(26.1 \%)$ and 34 patients $(20.1 \%)$ were categorized as intermediate-high or high risk, respectively. According to the NCCN-IPI, 42 cases (24.9\%) were classified as low risk, 51 as low-intermediate risk, 48 as intermediate-high and 28 cases as high risk. Notably, fewer patients were classified as low risk by the NCCN-IPI compared with the traditional IPI.

TMTV. The median TMTV of the entire population was $291.4 \mathrm{~cm}^{3}$ (50.3-1598.4 $\mathrm{cm}^{3}$; Fig. 1). The receiver operating curve (ROC) analysis demonstrated that the best TMTV cut-off value for PFS and OS estimation was $300 \mathrm{~cm}^{3}$ (data not shown). For PFS and OS, the area under the curve (AUC) values were 0.701 and 0.724 , respectively (data not shown). The sensitivity and specificity of the $300 \mathrm{~cm}^{3}$ cut-off for PFS were 75.1 and $67.3 \%$, respectively, while the sensitivity and specificity for OS were 76.6 and $66.7 \%$, respectively (data not shown).

The critical value of the ROC curve was used for Kaplan-Meier survival analysis. The results demonstrated 
Table I. Characteristics and scoring of the different systems.

\begin{tabular}{|c|c|c|c|c|c|c|}
\hline Characteristic & IPI & Score & NCCN-IPI & Score & M-PM & Score \\
\hline \multirow[t]{3}{*}{ Age, years } & NA & 0 & $>40$ to $\leq 60$ & 1 & NA & 0 \\
\hline & $>60$ & 1 & $>60$ to $\leq 75$ & 2 & $\geq 65$ & 1 \\
\hline & NA & 0 & $>75$ & 3 & NA & 0 \\
\hline Ann Arbor stage & III-IV & 1 & III-IV & 1 & NA & 0 \\
\hline \multirow[t]{2}{*}{ LDH, normalized } & $>1$ & 1 & $>1$ to $\leq 3$ & 1 & $>1$ & 1 \\
\hline & NA & 0 & $>3$ & 2 & NA & 0 \\
\hline Extranodal disease & $\geq 2$ & 1 & NA & 0 & NA & 0 \\
\hline${ }^{a}$ Distinct extranodal disease & NA & 0 & Any & 1 & NA & 0 \\
\hline Performance status & $\geq 2$ & 1 & $\geq 2$ & 1 & $\geq 2$ & 1 \\
\hline $\mathrm{COO}$ & NA & 0 & NA & 0 & NA & 0 \\
\hline TMTV, $\mathrm{cm}^{3}$ & NA & 0 & NA & 0 & $\geq 300$ & 1 \\
\hline Maximum score & NA & 5 & NA & 8 & NA & 4 \\
\hline
\end{tabular}

${ }^{a}$ Extranodal involvement of bone marrow, central nervous system, liver/gastrointestinal tract, or lung. IPI, international prognostic index; NCCN, National Comprehensive Cancer Network; M-PM, modified prognostic model; LDH, lactate dehydrogenase; COO, cell of origin; TMTV, total metabolic tumor volume; NA, not applicable.

that TMTV was a reliable predictor of OS at the univariable level (Table III). As presented in Fig. 2, the 5-year PFS rate of patients with high TMTV ( $\geq 300 \mathrm{~cm}^{3}, \mathrm{n}=94,55.6 \%$ ) was $38.3 \%$, while that of patients with low TMTV $\left(<300 \mathrm{~cm}^{3}, \mathrm{n}=75,44.4 \%\right)$ was $72 \%(\mathrm{P}<0.001)$. The 5-year OS rate of patients with high TMTV was $44.7 \%$, while that of patients with low TMTV was $80 \%(\mathrm{P}<0.001)$. In addition, significant differences were observed in OS between patients with TMTV values above and below $300 \mathrm{~cm}^{3}$ at the multivariate level [hazard ratio (HR), 4.21; 95\% confidence interval (CI), 2.71-7.32; $\mathrm{P}<0.001$; Table III].

Univariate and multivariate analyses. As presented in Table III, the following prognostic factors were assessed in the univariate and multivariable analyses: Age ( $<65$ years vs. $\geq 65$ years), disease stage (I-II vs. III-IV), ECOG performance status (0-1 vs. 2-4), B-symptoms (yes vs. no), LDH level (normal vs. elevated), the number of extranodal sites involved (0-1 vs. $\geq 2$ ), cell of origin (GCB vs. Non-GCB), bulky disease (yes vs. no), bone marrow involvement (yes vs. no) and TMTV ( $\geq 300 \mathrm{~cm}^{3}$ vs. $\left.<300 \mathrm{~cm}^{3}\right)$. Univariate analysis demonstrated that age $\geq 65$ years $(\mathrm{P}<0.001), \mathrm{B}$-symptoms $(\mathrm{P}=0.019)$, elevated LDH levels $(\mathrm{P}<0.001)$, ECOG performance status $2-4(\mathrm{P}=0.011)$, advanced stage $(\mathrm{P}=0.015)$, number of extranodal sites $>1 \quad(\mathrm{P}=0.013)$, bulky disease $(\mathrm{P}=0.033)$, bone marrow involvement $(\mathrm{P}=0.024)$ and TMTV $\geq 300 \mathrm{~cm}^{3}(\mathrm{P}<0.001)$ were all associated with poor prognosis. However, multivariate analysis demonstrated that only age $\geq 65$ years (HR, 2.14; 95\% CI, 1.20-4.41; $\mathrm{P}=0.002$ ), B-symptoms (HR, 2.24; 95\% CI, 1.38-4.36; P=0.016), elevated serum LDH levels (HR, 4.21; 95\% CI, 2.12-14.54; P<0.001), ECOG performance status 2-4 (HR, 3.32; 95\% CI, 2.45-6.62; $\mathrm{P}=0.025)$ and TMTV $\geq 300 \mathrm{~cm}^{3}(\mathrm{HR}, 4.21 ; 95 \% \mathrm{CI}, 2.71-7.32$; $\mathrm{P}<0.001)$ were considered independent prognostic factors.

Comparison of the M-PM with existing prognostic indexes. In the rituximab era, the M-PM model presented here combined metabolic parameters and clinical characteristics into a new integrative prognostic factor (Table I). According to the number of IPI risk factors, patients were distributed into four different risk groups. However, the IPI failed to effectively differentiate between the intermediate-high group and the high-risk group. As presented in Fig. 3, the 5-year PFS rate of patients at high risk was $41.2 \%$ and the OS rate was $50.8 \%$, whereas those at intermediate-high risk had a 5-year PFS rate of 52.3\% and an OS rate of $60.4 \%$ ( $\mathrm{P}=0.017$ for $\mathrm{PFS} ; \mathrm{P}=0.028$ for $\mathrm{OS})$. The NCCN-IPI also divided patients into four different risk groups. Each group had significantly different 5-year OS and PFS rates, and the index had a better discriminative ability compared with IPI. According to the NCCN-IPI, the 5-year PFS rate of patients at intermediate-high risk was $45.8 \%$ and the 5-year OS rate was $54.3 \%$, while the 5-year PFS rate of patients at high risk was $28.6 \%$ and the 5-year OS rate was $39.4 \%$ ( $\mathrm{P}=0.004$ for PFS; $\mathrm{P}=0.012$ for OS) (Table IV and Fig. 3).

Patients were also divided into four different risk groups by the M-PM, namely the low risk, low-intermediate risk, intermediate-high risk and high risk groups. The groups had a median follow-up time of 61, 58, 59 and 60 months, respectively. As presented in Table IV, the 5-year PFS rates of the four groups were $81.2,61.5,43.2$ and $23.5 \%$, respectively, while the 5-year OS rates were 92.4, 70.6, 52.3 and 24.5\%, respectively $(\mathrm{P}<0.001$ for PFS and OS; Fig. 3). The M-PM identified a group with even worse outcomes, with a 5-year OS rate of only $24.5 \%$, which neither the NCCN-IPI or the IPI identified. Thus, it was concluded that the predictive value of the M-PM was significantly stronger compared with the IPI and the NCCN-IPI for predicting high risk DLBCL $(\mathrm{P}<0.01)$. This high-risk group in the M-PM only represented a small number of patients $(10.1 \%)$, which was lower than that identified by the NCCN-IPI (16.6\%) and the IPI (20.1\%) (Table IV).

\section{Discussion}

DLBCL is a disease with biological heterogeneity, which is reflected in the different curative effects and survival of 
Table II. Clinical characteristics of patients $(n=169)$.

Characteristic Number of patients, n (\%)

$\begin{array}{lr}\text { Age, years } & \\ <65 & 120(71.0) \\ \geq 65 & 49(29.0) \\ \text { Sex } & \\ \text { Male } & 90(53.3) \\ \text { Female } & 79(46.7)\end{array}$

Presence of B-symptoms

No

$118(69.8)$

Yes

Performance status

$0-1$

$141(83.4)$

$\geq 2$

\section{Serum LDH}

Normal

$70(41.4)$

Elevated

Stage

I-II

III-IV

Extranodal involvement

$<2$

$126(74.6)$

$\geq 2$

$\mathrm{BM}$ involvement

$\begin{array}{lr}\text { Absent } & 146(86.4) \\ \text { Present } & 23(13.6) \\ \text { IPI } & \\ \text { Low, 0-1 } & 56(33.1) \\ \text { Low-intermediate, 2 } & 35(20.7) \\ \text { High-intermediate, } 3 & 44(26.1) \\ \text { High, 4-5 } & 34(20.1) \\ \text { Subtype } & \\ \text { GCB } & 72(42.6) \\ \text { Non-GCB } & 97(57.4) \\ \text { NCCN-IPI } & \\ \text { Low, 0-1 } & 42(24.9) \\ \text { Low-intermediate, 2-3 } & 51(30.1) \\ \text { High-intermediate, 4-5 } & 48(28.4) \\ \text { High, } \geq 6 & 28(16.6) \\ \text { Therapy } & \\ \text { RCHOP } & 150(88.8) \\ \text { RminiCHOP } & 19(11.2) \\ \text { Bulky disease } & \\ \text { No } & 144(85.2) \\ \text { Yes } & 25(14.8) \\ \end{array}$

ECOG; Eastern Cooperative Oncology Group; LDH, lactate dehydrogenase; BM, bone marrow; IPI, international prognostic index; GCB, germinal-center B-cell-like; NCCN, National Comprehensive Cancer Network; RCHOP, rituximab, cyclophosphamide, doxorubicin, vincristine and prednisone.

patients (2-4). The IPI is the most recognized and widely used prognostic evaluation model in DLBCL (6). In the rituximab era, the cure rate of DLBCL has improved, and the value of IPI's prognostic risk stratification has weakened, particularly among intermediate-high risk and high-risk groups $(8,27)$. In addition, NCCN-IPI and other prognostic evaluation systems cannot sufficiently distinguish high risk patients with a short survival time $(28,29)$. Thus, it remains critical to develop a more accurate prognostic model for DLBCL.

Common prognostic indexes of lymphoma include age, ECOG score and increased LDH levels, which are associated with a short survival time in DLBCL (6). In the original IPI model, the age limit was set to 60 years, which represented the demarcation point for myeloablative therapy and stem cell transplantation at the time (30). Currently, this restriction is no longer in place (30). With the extensive application of growth factors and rituximab, an increasing number of elderly patients have received sufficient immunochemotherapy (30). Thus, in the novel prediction model presented here, the age limit was altered to 65 years. The results of the present study confirmed that age ( $\geq 65$ years) is a key prognostic indicator. Notably, age ( $<65$ years) is also commonly used as an age node for dose-intensified immunochemotherapy or hematopoietic stem cell transplantation in mantle cell lymphomas (30).

Disease stage is a crude substitute for total tumor burden, which is illustrated by bulky stage I disease vs. stage IV lesions, with extensive but small extranodal lesions (31). FDG-PET/CT uses quantitative indicators of metabolically active tissues, such as TMTV, as indicators of tumor volume (31). In previous studies, the prognosis of patients with DLBCL was often stratified based on interim PET-CT parameters, such as the Deauville score $(32,33)$. The prognostic model presented here is based on baseline PET-CT parameters and clinical markers, and can predict the prognosis of patients earlier. The Maximum Standardized Uptake Value (SUVmax) is the most common metabolic parameter used in the clinic (34-37). However, measurement of SUVmax can only detect the most obvious metabolic activity of a tumor at a single site, and is unable to reflect the metabolic activity of the whole tumor, the size and volume of the tumor (34). Furthermore, several factors affect the accuracy of SUVmax, such as uptake interval, injection dose, injection leakage, tumor size and heterogeneity, blood sugar and hormone levels $(34,35)$. Thus, the prognostic value of SUVmax in DLBCL remains controversial $(36,37)$. TMTV and TLG reflect tumor volume and tumor activity (38). Our previous study demonstrated that TMTV is a more robust predictor of survival than TLG (39). Thus, TMTV was incorporated into the novel prognostic model presented here.

Previous studies have reported that TMTV has a strong predictive value for newly treated patients with DLBCL $(40,41)$. Higher TMTV is significantly associated with worse PFS and OS in patients with DLBCL $(19,20,42,43)$. Previous studies have also demonstrated that TMTV measured on $18 \mathrm{~F}-\mathrm{FDG}$ $\mathrm{PET} / \mathrm{CT}$ can be used as an important index in determining the prognosis of DLBCL $(19,43)$. However, there is still insufficient consensus on the calculation of TMTV. Currently, the two most common methods are based on the fixed threshold of SUV 2.5 (MTV 2.5) and the use of 41\% SUVmax isocontour (MTV 41) $(41,44)$. These methods are based on the principle of the fixed threshold to calculate the metabolism of local tumors $(41,44)$. The European Association of Nuclear Medicine recommends a SUVmax threshold of $41 \%$, which 
Table III. Multivariate analysis of variables for overall survival.

\begin{tabular}{|c|c|c|c|c|}
\hline \multirow[b]{2}{*}{ Variable (risk factor) } & \multicolumn{2}{|c|}{ Univariate } & \multicolumn{2}{|c|}{ Multivariate } \\
\hline & HR $(95 \%$ CI $)$ & P-value & HR $(95 \%$ CI $)$ & P-value \\
\hline Age, years (65 vs. $\geq 65)$ & $3.32(1.52-6.13)$ & $<0.001$ & $2.14(1.20-4.41)$ & 0.002 \\
\hline${ }^{\text {a} B}$-symptoms, Yes vs. No & $1.54(1.16-3.26)$ & 0.019 & $2.24(1.38-4.36)$ & 0.016 \\
\hline Cell of origin, GCB vs. Non-GCB & NS & & NS & \\
\hline Serum LDH, normal vs. elevated & $3.29(1.79-9.12)$ & $<0.001$ & $4.21(2.12-14.54)$ & $<0.001$ \\
\hline ECOG PS, 0-1 vs. 2-4 & $2.65(2.16-5.72)$ & 0.011 & $3.32(2.45-6.62)$ & 0.025 \\
\hline Ann Arbor stage, I-11 vs. III-IV & $3.11(1.88-5.22)$ & 0.015 & NS & \\
\hline Number of extranodal sites, $0-1$ vs. $\geq 2$ & $1.89(1.16-5.51)$ & 0.013 & NS & \\
\hline TMTV, $\mathrm{cm}^{3}(\geq 300$ vs. $<300)$ & $3.13(2.43-6.76)$ & $<0.001$ & $4.21(2.71-7.32)$ & $<0.001$ \\
\hline Bone marrow involvement, Yes vs. No & $2.37(1.27-5.43)$ & 0.024 & NS & \\
\hline bBulky mass, Yes vs. No & $1.37(1.19-4.21)$ & 0.033 & NS & \\
\hline
\end{tabular}

${ }^{\mathrm{a} B}$-symptoms were defined as night sweats, disease-related fevers, or weight loss $\geq 10 \%$ of body weight. ${ }^{b}$ Tumor size of bulky mass was $\geq 7.5 \mathrm{~cm}$. GCB, germinal-center B-cell-like; LDH, lactate dehydrogenase; ECOG; Eastern Cooperative Oncology Group; PS, performance status; TMTV, total metabolic tumor volume; HR, hazard ratio; CI, confidence interval; NS, no significance.
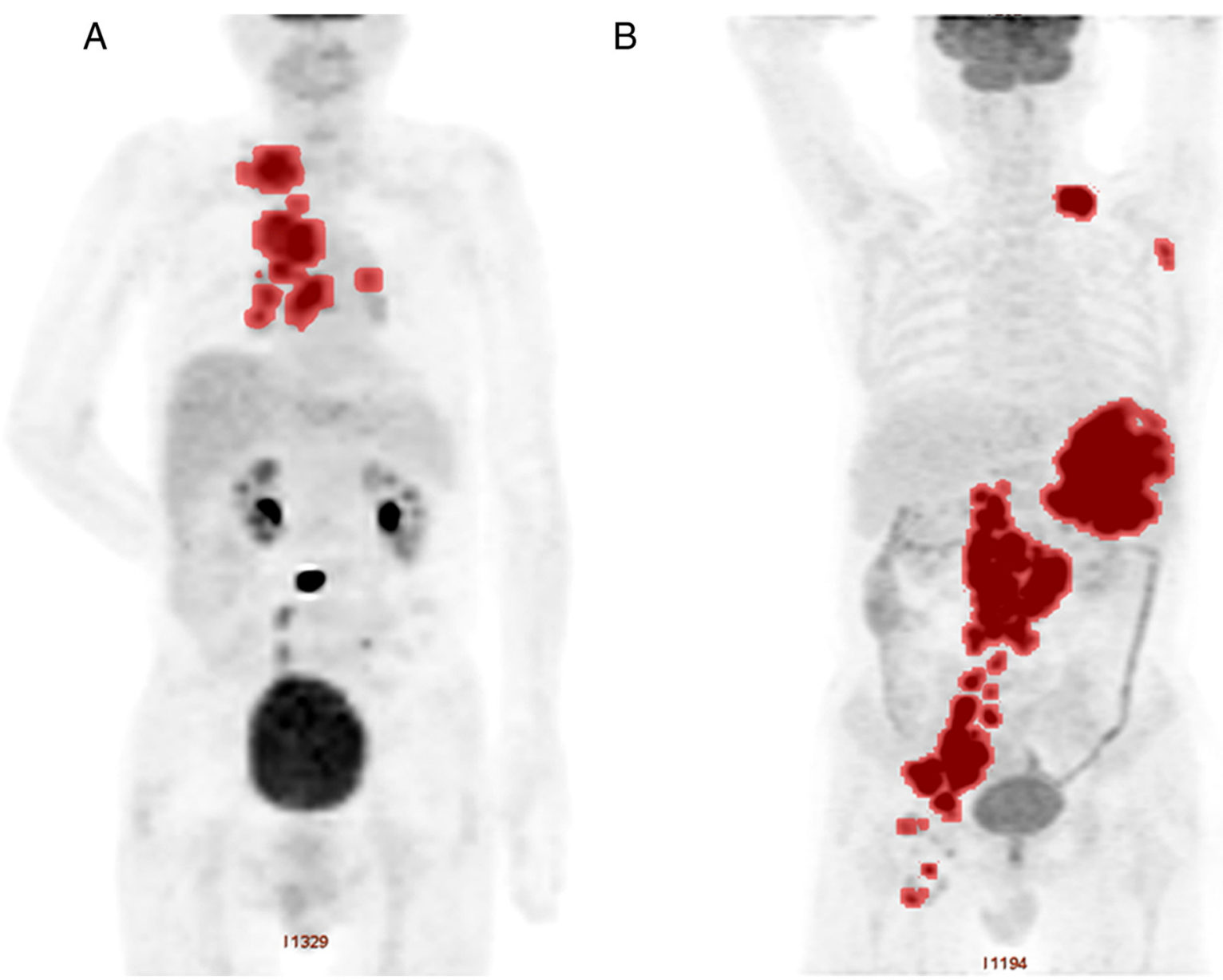

Figure 1. Patients with high and low TMTV. (A) TMTV was $213 \mathrm{~cm}^{3}$. (B) TMTV was 1,448 $\mathrm{cm}^{3}$. TMTV, total metabolic tumor volume.

has been used in patients with DLBCL with good interobserver repeatability (40). Given that the patients included in these studies had different ethnicities and research methods, different cut-off values were used $(20,40,45)$. The results of the present study demonstrated that TMTV $\geq 300 \mathrm{~cm}^{3}$ was significantly associated with poor prognosis.

High TMTV was significantly associated with advanced tumor stage and bulky disease $(9,14,46)$. High TMTV often 
Table IV. 5-year overall survival rates and distribution of patients in the risk groups using IPI, NCCN-IPI and M-PM scores.

\begin{tabular}{|c|c|c|c|c|c|c|c|c|c|}
\hline \multirow[b]{2}{*}{ Risk level } & \multicolumn{3}{|c|}{ IPI } & \multicolumn{3}{|c|}{ NCCN-IPI } & \multicolumn{3}{|c|}{ M-PM } \\
\hline & Score $(\%)$ & $\begin{array}{c}\text { 5-year } \\
\text { PFS, \% }\end{array}$ & $\begin{array}{l}\text { 5-year } \\
\text { OS, \% }\end{array}$ & Score $(\%)$ & $\begin{array}{c}\text { 5-year } \\
\text { PFS, \% }\end{array}$ & $\begin{array}{l}\text { 5-year } \\
\text { OS, \% }\end{array}$ & Score $(\%)$ & $\begin{array}{c}\text { 5-year } \\
\text { PFS, \% }\end{array}$ & $\begin{array}{l}5 \text {-year } \\
\text { OS, \% }\end{array}$ \\
\hline Low & $0-1(33.1)$ & 82.1 & 90.8 & $0-1(24.9)$ & 83.3 & $93.8 \%$ & $0-1(40.8)$ & 81.2 & 92.4 \\
\hline Low-intermediate & $2(20.7)$ & 71.4 & 78.4 & $2-3(30.1)$ & 68.6 & $76.5 \%$ & $2(23.1)$ & 61.5 & 70.6 \\
\hline Intermediate-high & $3(26.1)$ & 52.3 & 60.4 & $4-5(28.4)$ & 45.8 & $54.3 \%$ & $3(26.0)$ & 43.2 & 52.3 \\
\hline High & $4-5(20.1)$ & 41.2 & 50.8 & $6-8(16.6)$ & 28.6 & $39.4 \%$ & $4(10.1)$ & 23.5 & 24.5 \\
\hline
\end{tabular}

IPI, international prognostic index; NCCN, National Comprehensive Cancer Network; M-PM, modified prognostic model; PFS, progression-free survival; OS, overall survival.
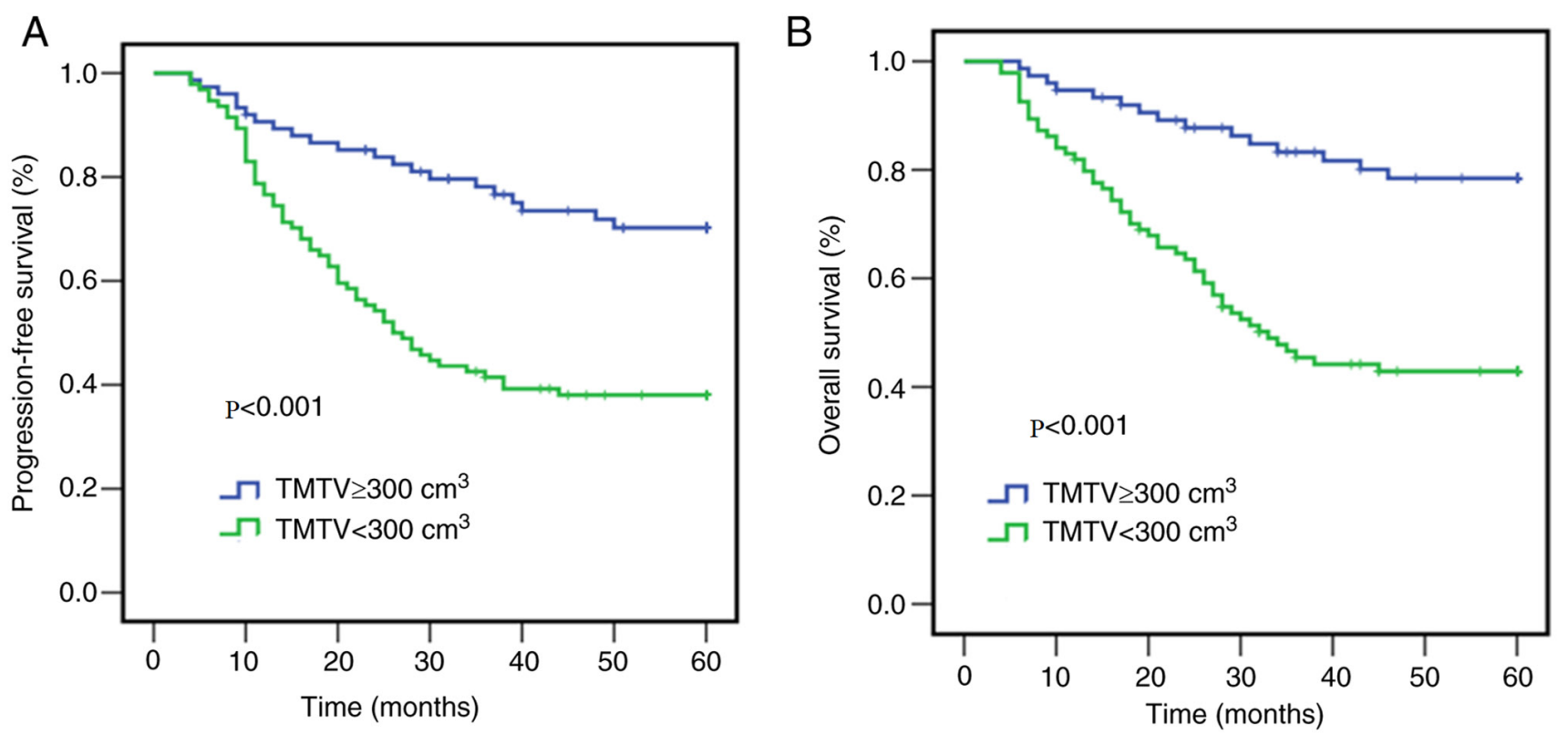

Figure 2. Kaplan-Meier analysis on (A) progression-free survival and (B) overall survival of patients based on TMTV. TMTV, total metabolic tumor volume.

represents a large tumor load and it may eventually replace the traditional IPI factors reflecting tumor load, such as extranodal diseases and Ann Arbor stage (9,14,46). Thus, it would be useful to add indicators associated with tumor metabolic characteristics to the current prognostic model in the form of quantitative PET indicators.

Some studies have included the functional parameters of PET into the prognostic evaluation model of DLBCL $(32,47,48)$. However, most prognostic models are based on the results of interim PET-CT indicators $(32,47)$. The present study predominantly used baseline TMTV and clinical indicators to predict the prognosis of DLBCL. To the best of our knowledge, the M-PM presented here is the first prognostic model to combine PET metabolic parameters and clinical characteristics in the rituximab era. According to the M-PM, there were 40.8, 33.1, 26.0 and $10.1 \%$ of patients with a low, low-intermediate, intermediate-high, and high risk, respectively.

Patients with low or intermediate risk can be cured by the RCHOP regimen (49); however, an unmet clinical requirement for patients at high risk remains. The M-PM can effectively identify this group of exceedingly high-risk patients. Future clinical trials should aim to maximize disease control and survival in high risk patients and develop promising targeted drugs.

The present study was not without limitations. First, it was a single-center, retrospective study with a moderate sample size, so there may have been some statistical errors. Secondly, the calculation of TMTV is time-consuming and the current calculation method is not uniform. In addition, transplantation and CAR-T may also affect the overall survival of patients. In our studies, patients who relapsed or refractory did not receive CAR-T cell therapy and allogeneic hematopoietic stem cell transplantation. A total of four patients received autologous hematopoietic stem cell transplantation, of which two patients relapsed 2 years after transplantation. However, a small sample size will not affect the final outcome. In the context of modern treatment, the model presented here should be verified in prospective trials. Furthermore, the present study failed to predict time to next therapy using the novel model. Thus, further studies are required to confirm the results presented here. 

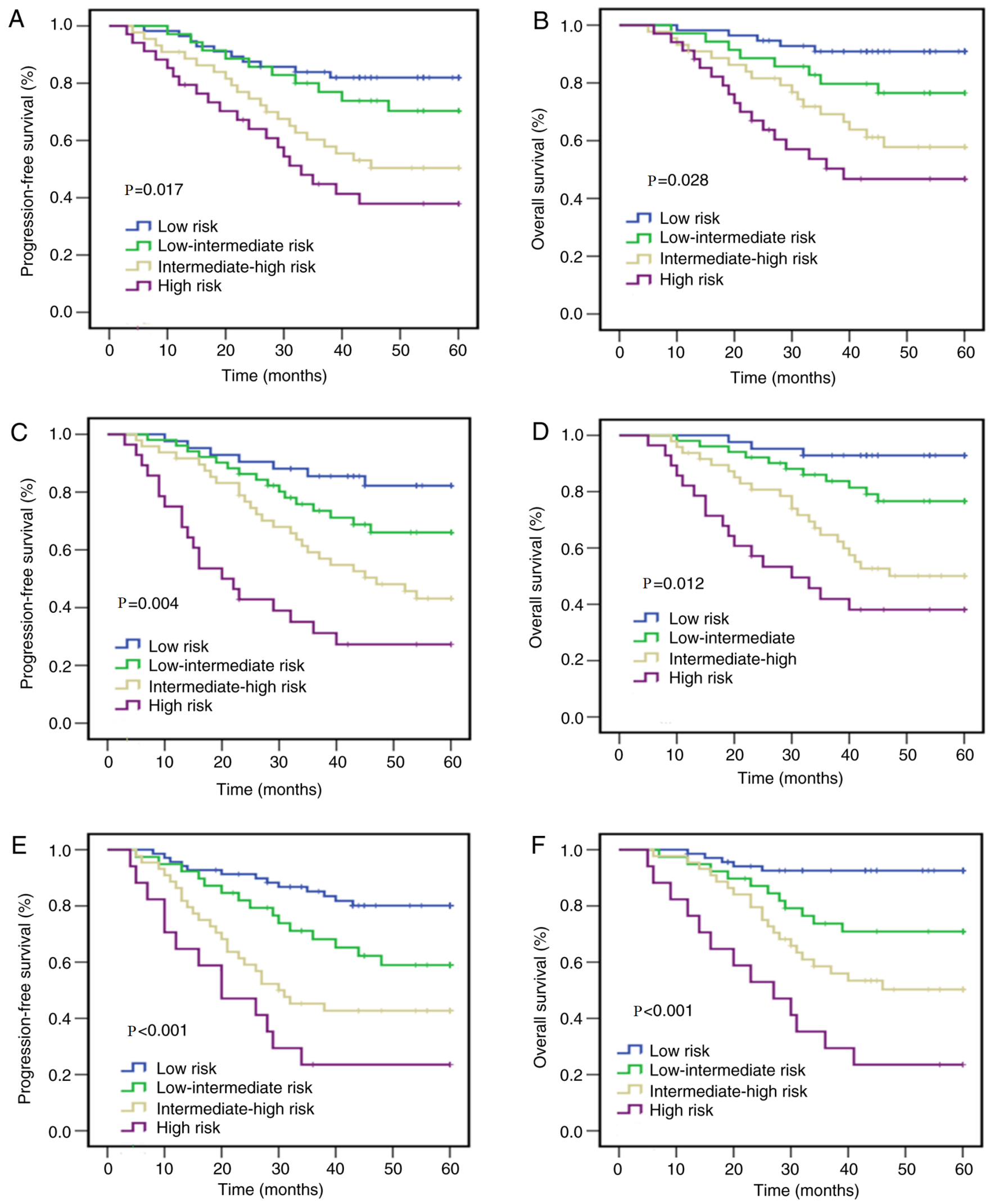

Figure 3. Kaplan-Meier analysis on progression-free survival and overall survival of patients with diffuse large B-cell lymphoma according to risk groups defined by the (A and B) IPI, (C and D) NCCN-IPI and (E and F) M-PM.

In conclusion, the present study proposed a novel modified prognostic model for newly diagnosed DLBCL, which consists of clinical parameters, biological parameters, and standardized imaging techniques. The results confirmed that in the rituximab era, the predictive value of the M-PM is more accurate than that of the IPI and the NCCN-IPI, particularly in the high risk DLBCL group. Furthermore, the M-PM can identify the high-risk population with a 5 -year OS rate $<30 \%$. Taken 
together, these results suggest that M-PM may be applied to prospective clinical trials. The prognostic model presented here requires verification through large-scale and multi-center trials. In addition, whether M-PM will retain its strong risk stratification ability in the context of targeted treatment and novel biomarkers also warrants further investigation.

\section{Acknowledgements}

Not applicable.

\section{Funding}

The present study was supported by the Natural Science Foundation of China (grant no. 81402575).

\section{Availability of data and materials}

The datasets used and/or analyzed during the present study are available from the corresponding author upon reasonable request.

\section{Authors' contributions}

HZ and WX designed the present study. PZ and LZ analyzed the experimental data and drafted the initial manuscript. LL, ZQ, LQ and SZ helped perform some experiments, obtained the data and revised the manuscript for important intellectual content. All authors have read and approved the final manuscript.

\section{Ethics approval and consent to participate}

The present study was approved by the Institutional Review Board of Tianjin Medical University Cancer Institute and Hospital (Tianjin, China). Written informed consent was obtained from all the patients.

\section{Patient consent for publication}

Not applicable.

\section{Competing interests}

The authors declare that they have no competing interests.

\section{References}

1. Jaffe ES: The 2008 WHO classification of lymphomas: Implications for clinical practice and translational research. Hematology Am Soc Hematol Educ Program 523-531, 2009.

2. Sehn LH and Gascoyne RD: Diffuse large B-cell lymphoma: Optimizing outcome in the context of clinical and biologic heterogeneity. Blood 125: 22-32, 2015.

3. Chapuy B, Stewart C, Dunford AJ, Kim J, Kamburov A, Redd RA, Lawrence MS, Roemer MGM, Li AJ, Ziepert M, et al: Molecular subtypes of diffuse large B cell lymphoma are associated with distinct pathogenic mechanisms and outcomes. Nat Med 24: 679-690, 2018.

4. Schmitz R, Wright GW, Huang DW, Johnson CA, Phelan JD, Wang JQ, Roulland S, Kasbekar M, Young RM, Shaffer AL, et al: Genetics and pathogenesis of diffuse large B-cell lymphoma. N Engl J Med 378: 1396-1407, 2018.
5. Cunningham D, Hawkes EA, Jack A, Qian W, Smith P, Mouncey P, Pocock C, Ardeshna KM, Radford JA, McMillan A, et al: Rituximab plus cyclophosphamide, doxorubicin, vincristine, and prednisolone in patients with newly diagnosed diffuse large B-cell non-Hodgkin lymphoma: A phase 3 comparison of dose intensification with 14-day versus 21 -day cycles. Lancet 381: 1817-1826, 2013.

6. International Non-Hodgkin's Lymphoma Prognostic Factors Project: A predictive model for aggressive non-Hodgkin's lymphoma. N Engl J Med 329: 987-994, 1993.

7. Bari A, Marcheselli L, Sacchi S, Marcheselli R, Pozzi S, Ferri P, Balleari E, Musto P, Neri S, Aloe Spiriti MA and Cox MC: Prognostic models for diffuse large B-cell lymphoma in the rituximab era: A never-ending story. Ann Oncol 21: 1486-1491, 2010.

8. Ziepert M, Hasenclever D, Kuhnt E, Glass B, Schmitz N, Pfreundschuh M and Loeffler M: Standard International prognostic index remains a valid predictor of outcome for patients with aggressive $\mathrm{CD} 20^{+} \mathrm{B}$-cell lymphoma in the rituximab era. J Clin Oncol 28: 2373-2380, 2010.

9. Zhou Z, Sehn LH, Rademaker AW, Gordon LI, Lacasce AS, Crosby-Thompson A, Vanderplas A, Zelenetz AD, Abel GA, Rodriguez MA, et al: An enhanced International Prognostic Index (NCCN-IPI) for patients with diffuse large B-cell lymphoma treated in the rituximab era. Blood 123: 837-842, 2014.

10. Adams HJ and Kwee TC: Prognostic value of interim FDG-PET in R-CHOP-treated diffuse large B-cell lymphoma: Systematic review and meta-analysis. Crit Rev Oncol Hematol 106: 55-63, 2016.

11. Nakaya A, Fujita S, Satake A, Nakanishi T, Azuma Y,Tsubokura Y, Hotta M, Yoshimura H, Ishii K, Ito T and Nomura S: Enhanced international prognostic index in Japanese patients with diffuse large B-cell lymphoma. Leuk Res Rep 6: 24-26, 2016.

12. Prochazka KT, Melchardt T, Posch F, Schlick K, Deutsch A, Beham-Schmid C, Weiss L, Gary T, Neureiter D, Klieser E, et al: NCCN-IPI score-independent prognostic potential of pretreatment uric acid levels for clinical outcome of diffuse large B-cell lymphoma patients. Br J Cancer 115: 1264-1272, 2016.

13. Montalbán C, Díaz-López A, Dlouhy I, Rovira J, Lopez-Guillermo A, Alonso S, Martín A, Sancho JM, García O, Sánchez JM, et al: Validation of the NCCN-IPI for diffuse large B-cell lymphoma (DLBCL): The addition of $\beta_{2}$-microglobulin yields a more accurate GELTAMO-IPI. Br J Haematol 176: 918-928, 2017.

14. Dybkaer K, Bøgsted M, Falgreen S, Bødker JS, Kjeldsen MK, Schmitz A, Bilgrau AE, Xu-Monette ZY, Li L, Bergkvist KS, et al: Diffuse large B-cell lymphoma classification system that associates normal B-cell subset phenotypes with prognosis. J Clin Oncol 33: 1379-1388, 2015.

15. Cheson BD, Pfistner B, Juweid ME, Gascoyne RD, Specht L, Horning SJ, Coiffier B, Fisher RI, Hagenbeek A, Zucca E, et al: Revised response criteria for malignant lymphoma. J Clin Oncol 25: 579-586, 2007.

16. Schot BW, Zijlstra JM, Sluiter WJ, van Imhoff GW, Pruim J, Vaalburg W and Vellenga E: Early FDG-PET assessment in combination with clinical risk scores determines prognosis in recurring lymphoma. Blood 109: 486-491, 2007.

17. Culpin RE, Sieniawski M, Angus B, Menon GK, Proctor SJ, Milne P, McCabe K and Mainou-Fowler T: Prognostic significance of immunohistochemistry-based markers and algorithms in immunochemotherapy-treated diffuse large B cell lymphoma patients. Histopathology 63: 788-801, 2013.

18. Wight JC, Chong G, Grigg AP and Hawkes EA: Prognostication of diffuse large B-cell lymphoma in the molecular era: Moving beyond the IPI. Blood Rev 32: 400-415, 2018

19. Kim J, Hong J, Kim SG, Hwang KH, Kim M, Ahn HK, Sym SJ, Park J, Cho EK, Shin DB and Lee JH: Prognostic value of metabolic tumor volume estimated by (18) F-FDG positron emission tomography/computed tomography in patients with diffuse large B-cell lymphoma of stage II or III disease. Nucl Med Mol Imaging 48: 187-195, 2014.

20. Sasanelli M, Meignan M, Haioun C, Berriolo-Riedinger A, Casasnovas RO, Biggi A, Gallamini A, Siegel BA, Cashen AF, Véra $\mathrm{P}$, et al: Pretherapy metabolic tumour volume is an independent predictor of outcome in patients with diffuse large B-cell lymphoma. Eur J Nucl Med Mol Imaging 41: 2017-2022, 2014.

21. Tout M, Casasnovas O, Meignan M, Lamy T, Morschhauser F, Salles G, Gyan E, Haioun C, Mercier M, Feugier P, et al: Rituximab exposure is influenced by baseline metabolic tumor volume and predicts outcome of DLBCL patients: A Lymphoma Study Association report. Blood 129: 2616-2623, 2017. 
22. Vitolo U, Trněný M, Belada D, Burke JM, Carella AM, Chua N, Abrisqueta P, Demeter J, Flinn I, Hong X, et al: Obinutuzumab or rituximab plus cyclophosphamide, doxorubicin, vincristine, and prednisone in previously untreated diffuse large B-cell lymphoma. J Clin Oncol 35: 3529-3537, 2017.

23. Hans CP, Weisenburger DD, Greiner TC, Gascoyne RD, Delabie J, Ott G, Müller-Hermelink HK, Campo E, Braziel RM Jaffe ES, et al: Confirmation of the molecular classification of diffuse large B-cell lymphoma by immunohistochemistry using a tissue microarray. Blood 103: 275-282, 2004

24. Cheson BD, Fisher RI, Barrington SF, Cavalli F, Schwartz LH, Zucca E, Lister TA; Alliance, Australasian Leukaemia and Lymphoma Group; Eastern Cooperative Oncology Group; European Mantle Cell Lymphoma Consortium, et al: Recommendations for initial evaluation, staging, and response assessment of Hodgkin and non-Hodgkin lymphoma: The Lugano classification. J Clin Oncol 32: 3059-3068, 2014.

25. Zhu L, Bian H, Yang L, Liu J, Chen W, Li X, Wang J, Song X, Dai D, Ye Z, et al: ${ }^{18}$ Fluorodeoxyglucose-positron emission tomography/computed tomography features of suspected solitary pulmonary lesions in breast cancer patients following previous curative treatment. Thorac Cancer 10: 1086-1095, 2019.

26. Zhao P, Li L, Zhou S, Qiu L, Qian Z, Liu X, Meng B and Zhang H: $\mathrm{CD} 5$ expression correlates with inferior survival and enhances the negative effect of p53 overexpression in diffuse large B-cell lymphoma. Hematol Oncol 37: 360-367, 2019.

27. Sehn LH, Berry B, Chhanabhai M, Fitzgerald C, Gill K Hoskins P, Klasa R, Savage KJ, Shenkier T, Sutherland J, et al: The revised International Prognostic Index (R-IPI) is a better predictor of outcome than the standard IPI for patients with diffuse large B-cell lymphoma treated with R-CHOP. Blood 109: 1857-1861,2007.

28. McMillan DC: Systemic inflammation, nutritional status and survival in patients with cancer. Curr Opin Clin Nutr Metab Care 12: 223-226, 2009 .

29. Li X, Zhang Y, Zhao W, Liu Z, Shen Y, Li J and Shen Z: The Glasgow Prognostic Score as a significant predictor of diffuse large B cell lymphoma treated with R-CHOP in China. Ann Hematol 94: 57-63, 2015.

30. Dreyling M, Campo E, Hermine O, Jerkeman M, Le Gouill S Rule S, Shpilberg O, Walewski J and Ladetto M; ESMO Guidelines Committee: Newly diagnosed and relapsed mantle cell lymphoma: ESMO Clinical Practice Guidelines for diagnosis, treatment and follow-up. Ann Oncol 28 (Suppl 4) iv62-iv71, 2017.

31. El-Galaly TC, Villa D, Gormsen LC, Baech J, Lo A and Cheah CY: FDG-PET/CT in the management of lymphomas: Current status and future directions. J Intern Med 284: 358-376, 2018.

32. Sun H, Yu Z, Ma N, Zhou J, Tian R, Zhao M and Wang T: Risk stratification of diffuse large B-cell lymphoma with interim PET/CT by combining deauville scores and international prognostic index. Cancer Manag Res 11: 9449-9457, 2019.

33. Yim SK, Yhim HY, Han YH, Jeon SY, Lee NR, Song EK, Jeong HJ, Kim HS and Kwak JY: Early risk stratification for diffuse large B-cell lymphoma integrating interim Deauville score and International Prognostic Index. Ann Hematol 98: 2739-2748, 2019.

34. Kostakoglu L and Chauvie S: Metabolic tumor volume metrics in lymphoma. Semin Nucl Med 48: 50-66, 2018.

35. Akamatsu G,Ikari Y,Nishida H, Nishio T, Ohnishi A, Maebatake A, Sasaki M and Senda M: Influence of statistical fluctuation on reproducibility and accuracy of SUVmax and SUVpeak: A Phantom Study. J Nucl Med Technol 43: 222-226, 2015.

36. Park S, Moon SH, Park LC, Hwang DW, Ji JH, Maeng CH, Cho SH, Ahn HK, Lee JY, Kim SJ, et al: The impact of baseline and interim PET/CT parameters on clinical outcome in patients with diffuse large B cell lymphoma. Am J Hematol 87: 937-940, 2012.
37. Gallicchio R, Mansueto G, Simeon V, Nardelli A, Guariglia R, Capacchione D, Soscia E, Pedicini P, Gattozzi D, Musto P and Storto G: F-18 FDG PET/CT quantization parameters as predictors of outcome in patients with diffuse large B-cell lymphoma. Eur J Haematol 92: 382-389, 2014.

38. Kim TM, Paeng JC, Chun IK, Keam B, Jeon YK, Lee SH, Kim DW, Lee DS, Kim CW, Chung JK, et al: Total lesion glycolysis in positron emission tomography is a better predictor of outcome than the International Prognostic Index for patients with diffuse large B cell lymphoma. Cancer 119: 1195-1202, 2013.

39. Zhao P, Zhu L, Song Z, Wang X, Ma W, Zhu X, Qiu L, Li L, Zhou S, Qian Z, et al: Combination of baseline total metabolic tumor volume measured on FDG-PET/CT and $\beta 2$-microglobulin have a robust predictive value in patients with primary breast lymphoma. Hematol Oncol 38: 493-500, 2020.

40. Cottereau AS, Lanic H, Mareschal S, Meignan M, Vera P, Tilly H, Jardin F and Becker S: Molecular profile and FDG-PET/CT total metabolic tumor volume improve risk classification at diagnosis for patients with diffuse large B-cell lymphoma. Clin Cancer Res 22: 3801-3809, 2016.

41. Mikhaeel NG, Smith D, Dunn JT, Phillips M, Møller H, Fields PA, Wrench D and Barrington SF: Combination of baseline metabolic tumour volume and early response on PET/CT improves progression-free survival prediction in DLBCL. Eur J Nucl Med Mol Imaging 43: 1209-1219, 2016.

42. Song MK, Chung JS, Shin HJ, Lee SM, Lee SE, Lee HS, Lee GW, Kim SJ, Lee SM and Chung DS: Clinical significance of metabolic tumor volume by PET/CT in stages II and III of diffuse large B cell lymphoma without extranodal site involvement. Ann Hematol 91: 697-703, 2012.

43. Xie M, Zhai W, Cheng S, Zhang H, Xie Y and He W: Predictive value of F-18 FDG PET/CT quantization parameters for progression-free survival in patients with diffuse large B-cell lymphoma. Hematology 21: 99-105, 2016.

44. Meignan M, Sasanelli M, Casasnovas RO, Luminari S, Fioroni F, Coriani C, Masset H, Itti E, Gobbi PG, Merli F and Versari A: Metabolic tumour volumes measured at staging in lymphoma: Methodological evaluation on phantom experiments and patients. Eur J Nucl Med Mol Imaging 41: 1113-1122, 2014

45. Ilyas H, Mikhaeel NG, Dunn JT, Rahman F, Møller H, Smith D and Barrington SF: Defining the optimal method for measuring baseline metabolic tumour volume in diffuse large B cell lymphoma. Eur J Nucl Med Mol Imaging 45: 1142-1154, 2018.

46. Gulec SA, Suthar RR, Barot TC and Pennington K: The prognostic value of functional tumor volume and total lesion glycolysis in patients with colorectal cancer liver metastases undergoing $90 \mathrm{Y}$ selective internal radiation therapy plus chemotherapy. Eur J Nucl Med Mol Imaging 38: 1289-1295, 2011.

47. Yang DH, Ahn JS, Byun BH, Min JJ, Kweon SS, Chae YS, Sohn SK, Lee SW, Kim HW, Jung SH, et al: Interim PET/CT-based prognostic model for the treatment of diffuse large B cell lymphoma in the post-rituximab era. Ann Hematol 92: 471-479, 2013.

48. Zhang YY, Song L, Zhao MX and Hu K: A better prediction of progression-free survival in diffuse large B-cell lymphoma by a prognostic model consisting of baseline TLG and \% $\triangle$ SUVmax. Cancer Med 8: 5137-147, 2019.

49. Friedberg JW and Fisher RI: Diffuse large B-cell lymphoma. Hematol Oncol Clin North Am 22: 941-952, ix, 2008.

This work is licensed under a Creative Commons Attribution-NonCommercial-NoDerivatives 4.0 International (CC BY-NC-ND 4.0) License. 